\title{
Outbreak of macrolide-resistant mycoplasma pneumoniae in a primary school in Beijing, China in 2018
}

\author{
Wen-Zeng Zhang ${ }^{1} \mathbb{D}$, Song-Jian Zhang ${ }^{1 *}$, Quan-Yi Wang ${ }^{2}$, Yin-Dong Li ${ }^{1}$, Hong-Bo Jing ${ }^{1}$, Guang-Yi Hu ${ }^{1}$ and Dan Wu ${ }^{1}$
}

\begin{abstract}
Background: On 7th June, 2018, a primary school in Beijing, China notified Shunyi CDC of an outbreak of acute respiratory disease characterized by fever and cough among students and resulting in nine hospitalization cases during the preceding 2 weeks. We started an investigation to identify the etiologic agent, find additional cases, develop and implement control measures.
\end{abstract}

Methods: We defined probable cases as students, teachers and other staffs in the school developed fever $\left(T \geq 37.5^{\circ} \mathrm{C}\right)$ with cough or sore throat; or a diagnosis of pneumonia during May 1-June 31, 2018. Confirmed cases were probable cases with Mycoplasma pneumoniae detected in oropharyngeal (OP) swabs by quantitative real-time polymerase chain reaction (qPCR). We searched case by reviewing school absenteeism records and interviewing students, teachers and staff in this school. Oropharyngeal swabs were collected from symptomatic students. Two qPCR) assay, a duplex qPCR assay, and sequencing were performed to determine the pathogen, genotype and macrolide resistance at the gene level, respectively.

Results: From May 1st to June 31st, 2018, we identified 55 cases (36 probable and 19 confirmed), of whom 25 (45\%) were hospitalized for complications. All cases were students, none of the teachers and other staffs in the school were with similar symptoms. The attack rate (AR) was 3.9\% (55/1398) for all students. The cases were mainly male (58\%), with an age range of 7-8 years (median: 7 years). $72 \%$ (18/25) of inpatients had radiograph findings consistent with pneumonia, and some cases were hospitalized for up to 4 weeks. Pathogen detection results indicated that Mycoplasma pneumonia (M. pneumoniae) P1 type 1 was the causative agent in this outbreak, and the strain harbored one point mutation of $\mathrm{A}$ to $\mathrm{G}$ at position 2063.

Conclusions: The infections by macrolide-resistant M. pneumoniae are not always mild and pneumonia was common and $\mathrm{M}$. pneumoniae could causes serious complications which require long-term hospitalization. In the future infectious disease prevention and control practice, M. pneumoniae should be paid more attention. It is necessary to establish and improve the pathogen and drug resistance surveillance system in order to prevent and control such mutated strains of M. pneumoniae from causing future outbreaks or epidemics in China.

Keywords: Mycoplasma pneumonia, Macrolide-resistant, Outbreak investigation, Primary school, China

\footnotetext{
* Correspondence: sy_fbk@163.com

${ }^{1}$ Beijing Shunyi Center for Disease Control and Prevention, Beijing, China

Full list of author information is available at the end of the article
}

(c) The Author(s). 2019 Open Access This article is distributed under the terms of the Creative Commons Attribution 4.0 International License (http://creativecommons.org/licenses/by/4.0/), which permits unrestricted use, distribution, and reproduction in any medium, provided you give appropriate credit to the original author(s) and the source, provide a link to the Creative Commons license, and indicate if changes were made. The Creative Commons Public Domain Dedication waiver (http://creativecommons.org/publicdomain/zero/1.0/) applies to the data made available in this article, unless otherwise stated. 


\section{Background}

Mycoplasma pneumoniae (M. pneumoniae) is a common pathogen of human respiratory tract infections (RTIs) and is a leading cause of community-acquired pneumonia (CAP) [1-3]. M. pneumoniae infections develop in persons of all ages, especially in children and teenagers [4]. M. pneumoniae infections range clinically from mild, self-limiting respiratory symptoms to radiographically confirmed pneumonia in an estimated 30\% of cases [5]. In rare cases, M. pneumoniae can cause extrapulmonary manifestations, including neurologic, dermatologic, hematologic and cardiac syndromes which can result in hospitalization and death [6, 7]. Macrolide antibiotics are commonly used drugs for the treatment of M. pneumoniae infection. With the widespread or inappropriate use of antibiotic, macrolide-resistant $\mathrm{M}$. pneumoniae (MRMP) has become an emerging threat worldwide [8-10]. In recent years, MRMP has become very serious in Asia [11-14].

M. pneumoniae is commonly associated with acute respiratory disease (ARD) and pneumonia outbreaks in semi-closed and closed settings such as care facility, kindergartens, schools and universities $[10,15,16]$. MRMP strain has been identified in some pneumonia outbreaks in recent years $[10,17]$. In China, M. pneumoniae infection is not a notifiable disease, most patients infected with MP are seldom symptomatic, patients rarely seek medical attention, and the clinical syndrome overlaps with other pneumonia etiologies, so the M. pneumoniae infection prevalence in the community was widely underestimated. However, several recent outbreaks of M. pneumoniae infections among children and adults have been reported, and macrolide-resistant strains have emerged $[18,19]$.

On 7 June, 2018, a primary school in Beijing, China notified Shunyi center for disease control and prevention (CDC) of an outbreak of acute respiratory disease characterized by fever and cough among students and resulting in nine hospitalization cases during the preceding 2 weeks. As part of the outbreak response, we conducted an epidemiologic investigation to identify the etiologic agent, find additional cases, develop and implement control measures. This is the largest outbreak of a macrolide-resistant strain of $M$. pneumoniae at a primary school in China in recent years.

\section{Methods}

\section{Epidemiologic investigation General situation}

The school has a total of 33 classes, including grades 15.All students are day students. There are two teaching buildings in the school. The first and second grades are located in the A teaching building, and the remaining grades are located in the $B$ teaching building. At the time of the outbreak, the primary school had 1398 students and 100 teachers and other staffs. A school doctor provides students with medical care.

\section{Outbreak finding/outbreak confirmation}

On 7 June, we identified 21 students suffering from a respiratory disease characterized by fever and cough in the Class 8 and 9 of Grade 1. Oropharyngeal (throat) swabs were collected from consenting patients presenting with ARD and specimens were tested using two multiplex quantitative polymerase chain reaction (qPCR) assay for 24 common respiratory pathogens (including 9 viruses, 14 bacteria and Pneumocystis pneumonia) at Shunyi CDC to identify the causative agent. Nine of the 12 (75\%) specimens were positive for M. pneumonia. We confirmed a M. pneumoniae outbreak in that school according to epidemiological and laboratory data.

\section{Case definition and finding}

To investigate the outbreak, the school absenteeism records were reviewed, students, teachers and other staffs in the school were interviewed, beginning June 8, 2018, to find cases of acute respiratory disease among students. The outpatient and inpatient records were reviewed and doctors in the hospitals were interviewed. The information regarding demographics, the process of illness, signs and symptoms, underlying conditions, clinical treatments, and extracurricular custody was collected. Retrospective record review was performed to identify cases diagnosed as early as May 1, 2018.

We defined probable cases as students, teachers and other staffs in the school developed fever $\left(\mathrm{T} \geq 37.5^{\circ} \mathrm{C}\right)$ with cough or sore throat; or a diagnosis of pneumonia during May 1-June 31, 2018. Confirmed cases were probable cases with $M$. pneumoniae detected in oropharyngeal swabs by qPCR.

\section{Specimen collection and nucleic acid extraction}

Oropharyngeal (OP) swabs were obtained from the students identified as probable cases and their close contacts who agreed to testing. OP swabs were placed in 2 $\mathrm{ml}$ of universal transport medium (UTM) and transported at $4{ }^{\circ} \mathrm{C}$ to the laboratory of the Shunyi CDC. Total nucleic acid (TNA) was extracted from $200 \mu \mathrm{l}$ of UTM from each swab specimen and eluted into $100 \mu \mathrm{l}$ using a MagNA Pure compact total nucleic acid isolation kit (Roche Applied Science) in accordance with the manufacturer instructions.

\section{Detection and genotyping}

All patient specimens were screened using two multiplex combined qPCR detection kits for Respiratory viruses and bacteria respectively (number product code: $\mathrm{CN12}-33$ and CN13-3, Uninovo Biological Technology Co. Ltd., Jiangsu, 
China) in order to identify the etiology of the outbreak. The kit for respiratory bacteria were specific for 15 respiratory pathogens, including: acinetobacter baumannii (Ab), chlamydia pneumoniae(C. pneumoniae), escherichia coli (E. coli), haemophilus influenza (Hi), Klebsiella pneumoniae (KP), Legionella pneumophila (Lp), moraxella catarrhalis (MC), mycoplasma pneumoniae (M. pneumoniae), Mycobacterium tuberculosis (Mtb), Staphylococcus aureus (S.aureus), streptococcus pneumoniae (S. pneumoniae), Streptococcus pyogenes $(S P)$, stenotrophomonas maltophilia (SMA), pseudomonas aeruginosa (PAE), and pneumocystis jiroveci pneumonia $(P C P)$. The kit for respiratory viruses were specific for 9 respiratory viruses, including: human parainfluenza virus types 1 to 4 (HPIV), adenovirus (ADV), metapneumovirus (MPV), human coronavirus types OC43/NL63/229E/HKU1 (HCOV), respiratory syncytial virus (RSV), human rhinovirus (HRV), influenza virus types $A / B / C$ (FLU), human enterovirus (HEV), and human bocavirus (HBOV). The multiplex qPCR was performed by previously described methods [20]. A duplex qPCR assay was used for P1 genotyping of M. pneumonia, and primers and probes were as previously described [21].

\section{Detection of macrolide resistance at the gene level}

Point mutations associated with resistance in domain $\mathrm{V}$ of 23S rRNA were detected. Genomic DNA of all M. pneumoniae was extracted using a QIAamp DNA minikit (Qiagen, Hilden Germany). The extracts were distributed into aliquots and saved at $-20^{\circ} \mathrm{C}$. A forward primer extending from position 1758 to position 1775 (GCAGTGAAGAACGAGGGG) and a verse primer extending from position 2684 to position 2664 (GTCCTC GCTTCGGTCCTCTCG) in the sequence of $\mathrm{M}$. pneumoniae 23S rRNA were used to amplify the domain $\mathrm{V}$ region of the 23S rRNA gene by PCR methods, as previously described [22]. The amplification products were sequenced by the Invitrogen Life Technologies (Shanghai, China).

\section{Statistical analysis}

All data were analyzed with SPSS 25.0 software (IBM, USA). Categorical variables were described with counts and percentages. Differences between medians were tested by the Mann-Whitney U test, and the Chi-square or Fisher's exact test was used to compare categorical variables. A $P$ value of less than 0.05 was considered statistically significant.

\section{Results}

\section{Epidemiologic investigation}

During May 1-June 31, 2018, a total of 55 cases were identified, including 19 confirmed and 36 probable cases. Illness onset occurred during May 14-June 28, 2018 and peaked at the beginning of June (Fig. 1). The first child developed ARD on 14 May, 2018, rested at home on the 15 th, and returned to school on the 16th. This child is a student of class 8 grade 1, and a member of sunflower dinner table. The "sunflower dinner table" here is a private institution which makes profit by providing lunch and dinner to students in noon and evening after school time, and it also provides space for students to have a nap in the noon. This patient, had a high fever $\left(39.0^{\circ} \mathrm{C}\right)$, sore throat, and cough, went to Shunyi maternal and child health Hospital of Beijing Children's Hospital, Beijing, China, for outpatient treatment on the afternoon of May 16, 2018. The initial diagnosis was bronchitis, and the later diagnosis was mycoplasma pneumonia. On May 28, the child's symptoms improved and returned to the school. With the resumption of the first patient, 54 cases with symptoms of ARD and pneumonia occurred one after another.

All 55 probable and confirmed cases of M. pneumoniae were students, none of the teachers and other staffs in the school exhibited similar symptoms. The attack rate (AR) of all students was 3.9\%(55/1398). Of the 55 cases, 48 (87\%) were grade 1 students, 7 (13\%) were grade 2 students. The outbreak involved 4 classes in the grade 1 and 2 . The overall attack rate of class was $22 \%$ $(55 / 248)$ (range $=2-58 \%)$. Among the 55 cases, $10(18 \%)$ were members of the sunflower dinner table. The AR of the sunflower table students was $23 \%(8 / 35)$. There was no significant difference in the attack rate between the two groups (Chi-Squares $=0.01, P=0.928$ ). The cases were mainly male (58\%), with an age range of $7-8$ years (median: 7 years), the above distribution characteristics are basically consistent with the distribution characteristics of all students.

A total of 53 patients (96\%) reported cough, 50 (91\%) fever, and 24 (44\%) sore throat. Twenty-five (45\%) of the patients were hospitalized for complications, including 2 with abnormal myocardial biomarker (CK-MB: > $30 \mathrm{U} / \mathrm{L}$ ) and 1 of whom with pleural effusion; eventually all cases were recovered. Radiographs were administered for all 25 inpatients with pneumonia diagnoses; 18 (72\%) of whom had findings consistent with pneumonia with radiographical indications. Eighteen (72\%) inpatients were treated with azithromycin, 9 (36\%) with betalactams, 9 (36\%) with multiple antibiotics, and 13 (52\%) with glucocorticoid, none of the patients was treated with quinolones or tetracyclines but the symptoms such as cough lasted for a long time in most cases, and some cases were hospitalized for up to 4 weeks (Table 1 ).

The median hospitalization period was 11 days (range $=2-28$ days), and the median duration of disease was 16 days (range $=6-34$ days).Among the 55 cases, the overall median time interval between onset to first visit to any medical institution was 1 day (range $=0-10$ days), the time interval before June 8 was 


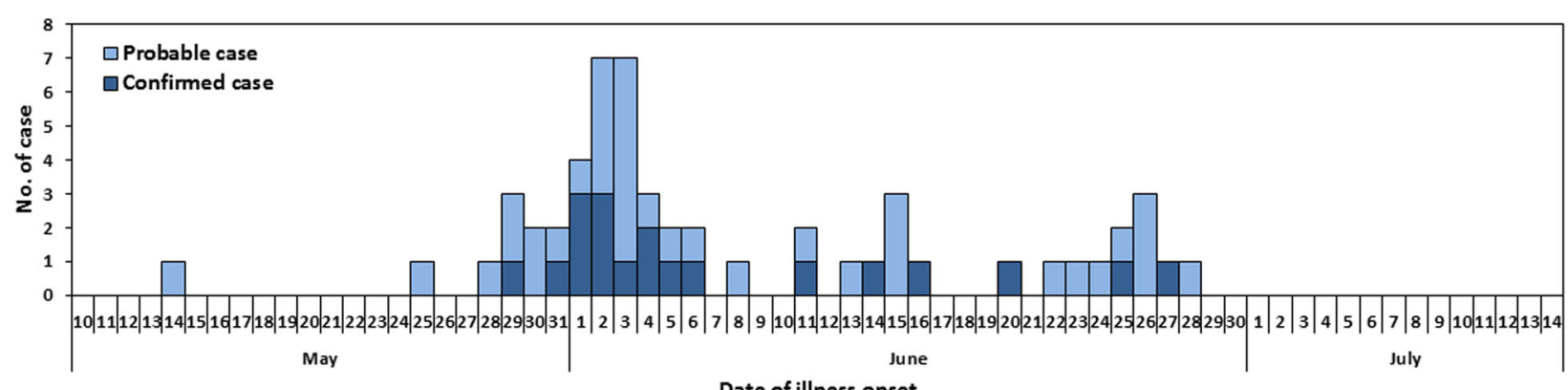

Date of illness onset

Fig. 1 Timeline of Mycoplasma pneumoniae outbreak in a primary school—Beijing, May-June 2018

Table 1 Number and percentage of patients with confirmed or probable M. pneumoniae cases among students in a primary school, by selected characteristics - Beijing, 2018

\begin{tabular}{|c|c|c|c|c|c|c|}
\hline \multirow[t]{2}{*}{ Characteristic } & \multicolumn{2}{|c|}{$\begin{array}{c}\text { Confirmed } \\
(n=19)\end{array}$} & \multicolumn{2}{|c|}{$\begin{array}{c}\text { Probable } \\
(n=36)\end{array}$} & \multicolumn{2}{|c|}{$\begin{array}{c}\text { Total } \\
(N=55)\end{array}$} \\
\hline & No. & (\%) & No. & (\%) & No. & $(\%)$ \\
\hline \multicolumn{7}{|l|}{ Sex } \\
\hline Men & 12 & (63) & 21 & (58) & 33 & (60) \\
\hline Women & 7 & (37) & 15) & $(42$ & 22 & (40) \\
\hline \multicolumn{7}{|l|}{ Grade } \\
\hline Grade 1 & 17 & (89) & 31 & (86) & 48 & (87) \\
\hline Grade 2 & 2 & (11) & 5 & (14) & 7 & (13) \\
\hline \multicolumn{7}{|l|}{ Symptom } \\
\hline Cough & 18 & (95) & 35 & (97) & 53 & (96) \\
\hline Fever & 17 & (89) & 33 & (92) & 50 & (91) \\
\hline Sore throat & 10 & (53) & 14 & (39) & 24 & (44) \\
\hline Pharyngeal wall congestion & 7 & (37) & 8 & (22) & 15) & $(27$ \\
\hline Body aches & 6 & (32) & 7 & (19) & 13 & (24) \\
\hline Headache & 6 & (32) & 6 & (17) & 12 & (22) \\
\hline Tonsil enlargement & 6 & (32) & 6 & (17) & 12 & (22) \\
\hline Runny nose & 2 & (11) & 2 & (6) & 4 & (7) \\
\hline Nasal congestion & 0 & $(0)$ & 2 & (6) & 2 & (4) \\
\hline \multicolumn{7}{|l|}{ Chest radiograph } \\
\hline No. of patients administered & 10 & (53) & 15 & (42) & 25 & (45) \\
\hline No. with findings consistent with pneumonia & 7 & (70) & 11 & (73) & 18 & $(72)$ \\
\hline \multicolumn{7}{|l|}{ Outcome } \\
\hline Outpatient & 9 & (47) & 21 & (58) & 30 & (55) \\
\hline Hospitalization & 10 & (53) & 15 & (42) & 25 & (45) \\
\hline \multicolumn{7}{|l|}{ Antibiotic treatment ${ }^{a}$} \\
\hline Azithromycin & 8 & (80) & 10 & (67) & 18 & (72) \\
\hline Beta-lactams $^{\mathrm{b}}$ & 4 & (40) & 5 & (33) & 9 & (36) \\
\hline Multiple antibiotics & 4 & (40) & 5 & (33) & 9 & (36) \\
\hline Glucocorticoid $^{c}$ & 5 & (50) & 8 & (53) & 13 & (52) \\
\hline Information missing & 1 & (10) & 5 & (33) & 6 & (24) \\
\hline
\end{tabular}

${ }^{a}$ Data from 25 hospitalized cases and the list of antibiotics is not mutually exclusive

Included latamoxef sodium, ceftizoxime, and cefmetazole

Included prednisone and methylprednisolone 
longer than cases onset on and after June $8(\mathrm{Z}=-$ $3.238, P<0.001)$.

Oropharyngeal swabs were collected from $56 \%(31 / 55)$ of all cases and tested by qPCR, 19 (61\%) specimens were positive for $\mathrm{M}$. pneumoniae and no other pathogens were identified. Nineteen positive specimens included 14 cases suffering from pneumonia (14/25), 5 with URI (5/30). One (5\%) of 20 close contact specimens was positive for M. pneumonia and the student was finally judged to be a carrier. The positive rate of mycoplasma in pneumonia cases was significantly higher than that of patients with URI and carriers (chi-square $=6.36$ and chi-square $=24.18 ; P<0.01$ and $P<0.001$ ). All 19 strains were classified as P1 type 1 by P1 genotyping of the primary specimens. The result of nucleotide sequence analysis of the domain $\mathrm{V}$ region of the $23 \mathrm{~S}$ rRNA gene in 7 primary specimens showed that the strain harbored one point mutation of A to $\mathrm{G}$ at position 2063.

\section{Public health response}

On June 8, 2018, Shunyi CDC guided the school to take the following prevention and control measures, including closure of two classes with the most morbidity in the first grade for 2 weeks, suspending of group activities, reinforcement of ventilation and disinfection in all classrooms and education regarding good health behaviors to reduce the risk of disease transmission. All cases were promptly treated outpatient or inpatient and discharged from school until afebrile for $\geq 48 \mathrm{~h}$. Shunyi CDC communicated with parents of students about respiratory infection prevention and control measures, including good hand hygiene and respiratory hygiene, and seeking medical attention when you have a cough and fever. Six dinner tables with cases were closed. Shunyi CDC and the relevant departments informed the dinner table around the school the epidemic situation. In order to characterize the possible continuing circulation of M. pneumoniae and identify the potential need for adjustments to control measures, an active surveillance for pneumonia was established in the primary school. The measure of screening the students for fever and active respiratory symptoms when students arrived at school was implemented.

\section{Discussion}

In China, M. pneumoniae infection is not a notifiable disease, so the prevalence of $\mathrm{M}$. pneumoniae infection in schools is unclear and the severity of M. pneumoniae outbreaks was still under discussion. However, several outbreaks of M. pneumoniae have been reported at schools in China, and macrolide-resistant strains have emerged $[18,19]$. This is the largest outbreak of a macrolideresistant strain of $\mathrm{M}$. pneumoniae at a primary school in China in recent years and this outbreak attracted widespread concerns from local governments, health administrative departments and public health departments. After taking control measures, the number of cases decreased gradually, and the time interval between onset to first visit to any medical institution was significantly shortened.

M. pneumoniae is spread through respiratory droplets; therefore, physical barriers may be effective for blocking spread of infection, which would be helpful in management of M. pneumoniae outbreak. Wang et al. [18] found that the major risk factor was the distance (less than $3 \mathrm{~m}$ ) between the school children at an outbreak of M. pneumoniae in a nursery school. In our study, the field epidemiological investigation result showed that the outbreak began in class 8 grade 1 and the sunflower dinner table where the first case studied and rest. Subsequently, cases began to appear in the neighboring class. This result was different from previous research result of outbreaks in two primary schools [19]. This result indicates that good environmental and hygienic conditions are important for the prevention and control of respiratory infections disease outbreaks.

This M. pneumoniae outbreak was identified after a significant number of acute respiratory disease cases were reported among students at Shunyi CDC. The multiplex qPCR assay for respiratory viruses and bacteria was used as the primary testing method in this investigation. The multiplex qPCR assay was useful for outbreaks in which the etiology is initially unknown, like this one, because it enables simultaneous testing for multiple pathogens within a specimen. After the outbreak's etiology was confirmed, active surveillance for probable cases and specimen collection for diagnostic testing began and clinicians frequently prescribed antibiotics on the basis of reports of a fever or cough rather than on patient evaluation or diagnostic test results. In our study, the positive rate of $\mathrm{M}$. pneumoniae in pneumonia cases was significantly higher than that of students with URI and carriers and all 19 strains were classified as P1 type 1. A reduction in the time between outbreak recognition and initiation of active surveillance with prioritized specimen collection will lead to appropriate patient treatment and implementation of timely and strict infection control measures to prevent morbidity and mortality.

MRMP isolates were first found in 1968 and various rates of macrolide resistance have been reported in recent M. pneumoniae surveillance [22]. Walter et al. reported that erythromycin-resistant strains of M. pneumoniae increased from $0 \%$ in 2002 to $30.6 \%$ in 2006 in Japan [23]. Zheng et al. reported that the MRMP rates increased from $17 \%$ in 2005 to $76 \%$ in 2006 and $100 \%$ in 2007 and 2008 in Shanghai, China [11].Wang et al. reported that the MRMP was at a high rate of more than $90 \%$ from 2008 to 2012 in Beijing [19]. The above research results showed 
that MRMP spread rapidly in parts of Asia. However, there have been few reports of outbreaks caused by MRMP in China. The strain isolated from this outbreak was macrolide resistant. In this outbreak, the more severe clinical signs and symptoms, the more hospitalizations with complications, the longer period of hospitalization, the longer duration of disease of all patients, and these results may be related to above finding.

Some studies have shown that the symptoms of infected macrolide-resistant strains are more severe than those of macrolide-sensitive strains [24-26]. In our study, pneumonia was most common symptoms among students who tested positive for M. pneumoniae strains during the outbreak. One of the cases was diagnosed as RMPP and hospitalized for 28 days for myocardial damage and pleural effusion. The results indicated that the clinical manifestations of patients infected with $\mathrm{M}$. pneumoniae are not always mild, and M. pneumoniae could causes serious complications requiring long-term hospitalization. In the future epidemic prevention and control work, M. pneumoniae should be paid more attention. It is necessary to establish and improve the test, report, and surveillance system for M. pneumoniae in China.

There were still a few limitations in our study. First and foremost, we did not collect specimens from every on of all 55 cases, only $56 \%$ cases had specimens tested by qPCR. Secondly, the M. pneumoniae isolation and culture work was not conducted, and the drug resistance test based on the in vitro drug sensitivity test was not carried out. All drug resistance results were based on nucleotide sequencing results and previous literature reports. Thirdly, some cases might have been infected in the community, but this probability is low because of the epidemiological time and person distribution and genotype identification.

\section{Conclusions}

This was a macrolide-resistant Mycoplasma pneumoniae outbreak that occurred in a primary school. The infections by macrolide-resistant strains are not always mild and pneumonia was common. M. pneumoniae could cause serious complications which require long-term hospitalization. We recommended Ministry of Health to establish and improve the pathogen and drug resistance surveillance system in order to prevent and control such mutated strains of $\mathrm{M}$. pneumoniae from causing future outbreaks or epidemics in China.

\section{Abbreviations}

AR: Attack rate; CAP: Community-acquired pneumonia; CDC: Centers for Diseases Control and Prevention; CK-MB: Creatine kinase-MB; M. pneumonia: Mycoplasma pneumonia; MRMP: Macrolide-resistant M. pneumonia; OP: Oropharyngeal; RMPP: Refractory Mycoplasma pneumoniae pneumonia; RTIs: Respiratory tract infections; URI: Upper respiratory tract infection

\section{Acknowledgements}

Not applicable.

\section{Authors' contributions}

SJZ led the outbreak investigation, collected data, revised the content and gave approval of the final manuscript. WZZ participated in protocol

development, data collection, analysis and writing of the first draft. GYH and DW participated in field investigations, data collection and analysis, dissemination of preliminary findings. QYW provided technical guidance for the outbreak investigation and data analysis. HBJ performed the laboratory investigations and participated in manuscript writing. YDL reviewed the first draft for content and made comments. All authors read and approved the final manuscript for publication and their concurrence statements are available if needed.

\section{Funding}

This work was supported by the Fund of Research and Development Program of Beijing Shunyi Health Planning Commission [grant number Wsjskyfzzx-z-04]. This fund provides financial support in the field investigation, specimen test, and data analysis.

\section{Availability of data and materials}

The datasets used and analyzed during the current study are available from the corresponding author upon reasonable request.

\section{Ethics approval and consent to participate}

Approval for the study was obtained from the ethics committee of Beijing Shunyi Center for Disease Control and Prevention (Shunyi CDC). The verbal consent was obtained from one guardian (either father or mother) of each patient before enrollment. In an outbreak investigation situation, the ethics committee approved this procedure to conduct an investigation after obtaining verbal consent.

\section{Consent for publication}

Not applicable.

\section{Competing interests}

The authors declare that they have no competing interests.

\section{Author details}

${ }^{1}$ Beijing Shunyi Center for Disease Control and Prevention, Beijing, China. ${ }^{2}$ Beijing Center for Disease Control and Prevention, Beijing, China.

Received: 17 November 2018 Accepted: 13 September 2019

Published online: 22 October 2019

\section{References}

1. Atkinson TP, Balish MF, Waites KB. Epidemiology, clinical manifestations, pathogenesis and laboratory detection of mycoplasma pneumonia infections. FEMS Microbiol Rev. 2008;32(6):956-73.

2. Principi N, Esposito S. Macrolide-resistant Mycoplasma pneumoniae: its role in respiratory infection. J Antimicrob Chemother. 2013;68:506-11. https:// doi.org/10.1093/jac/dks457.

3. Bajantri B, Venkatram S, Diaz-Fuentes G. Mycoplasma pneumoniae: a potentially severe infection. J Clin Med Res. 2018;10(7):535-44. https://doi. org/10.14740/jocmr3421w.

4. Cao B, Zhao CJ, Yin YD, Zhao F, Song SF, Bai L, Zhang JZ, Liu YM, Zhang YY, Wang $\mathrm{H}$, et al. High prevalence of macrolide resistance in Mycoplasma pneumoniae isolates from adult and adolescent patients with respiratory tract infection in China. Clin Infect Dis. 2010;51(2):189-94.

5. Winchell JM. Mycoplasma pneumoniae - a National Public Health perspective. Curr Pediatr Rev. 2013;9:324-33. https://doi.org/10.2174/15733963113099990009.

6. Tsiodras S, Kelesidis I, Kelesidis T, Stamboulis E, Giamarellou H. Central nervous system manifestations of Mycoplasma pneumoniae infections. J Inf Secur. 2005;51(5):343-54. https://doi.org/10.1016/j.jinf.2005.07.005.

7. Olson D, Watkins LK, Demirjian A, Lin X, Robinson CC, Pretty K, Benitez AJ, et al. Outbreak of Mycoplasma pneumoniae-associated Stevens-Johnson syndrome. Pediatrics. 2015;136(2):e386-94. https://doi.org/10.1542/peds.2015-0278.

8. Peuchant O, Menard A, Renaudin H, Morozumi M, Ubukata K, Bebear CM, Pereyre S. Increased macrolide resistance of mycoplasma pneumonia in 
France directly detected in clinical specimens by qPCR and melting curve analysis. J Antimicrob Chemother. 2009;64:52-8.

9. Dumke R, von Baum H, Luck PC, Jacobs E. Occurrence of macrolide-resistant Mycoplasma pneumoniae strains in Germany. Clin Microbiol Infect. 2010;16:613-6.

10. Diaz MH, Benitez AJ, Winchell JM. Investigations of Mycoplasma pneumoniae infections in the United States: trends in molecular typing and macrolide resistance from 2006 to 2013. J Clin Microbiol. 2015;53(1):124-30. https://doi.org/10.1128/JCM.02597-14.

11. Liu Y, Ye X, Zhang H, Xu X, Li W, Zhu D, et al. Antimicrobial suscepetibility of Mycoplasma pneumoniae isolates and molecular analysis of macrolideresistant from Shanghai, China. Antimicrob Agents Chenother. 2009;53(5): 2160-2. https://doi.org/10.1128/AAC.01684-08.

12. Zhao F, Liu G, Wu J, Cao B, Tao X, He L, et al. Surveillance of macrolide-resistant mycoplasma pneumonia in Beijing, China, from 2008 to 2012. Antimicrob Agents Chemother. 2013;57:1521-3. https://doi.org/10.1128/AAC.02060-12

13. Ho PL, Law PY, Chan BW, Wong CW, To KK, Chiu SS, et al. Emergence of macrolide-resistant Mycoplasma pneumoniae in Hong Kong is linked to increasing macrolide resistance in multilocus variable-number tandem-repeat analysis type 45-7-2. J Clin Microbiol. 2015;53:3560-4. https://doi.org/10.1128/JCM.01983-15.

14. Tanaka T, Oishi T, Miyata I, et al. Macrolide-resistant Mycoplasma pneumoniae infection, Japan, 2008-2015. Emerg Infect Dis. 2017;23:1703-6. https://doi.org/10.3201/eid2310.170106.

15. Centers for Disease Control and Prevention (CDC). Mycoplasma pneumoniae outbreak at a university - Georgia, 2012. MMWR Morb Mortal Wkly Rep. 2013;62(30):603-6.

16. Hastings DL, Harrington KJ, Kutty PK, Rayman RJ, Spindola D, Diaz MH, Thurman KA, Winchell JM, Safranek TJ. Centers for Disease Control and Prevention (CDC). Mycoplasma pneumoniae outbreak in a long-term care facility-Nebraska, 2014. MMWR Morb Mortal Wkly Rep. 2015;64:296-9.

17. Suzuki Y, Itagaki T, Seto J, Kaneko A, Abiko C, Mizuta K, Matsuzaki Y. Community outbreak of macrolide-resistant Mycoplasma pneumoniae in Yamagata, Japan in 2009. Pediatr Infect Dis J. 2013;32:237-40. https://doi. org/10.1097/INF.0b013e31827aa7bd.

18. Wang Y, Qiu S, Yang G, Song L, Su W, Xu Y, et al. An outbreak of Mycoplasma pneumoniae caused by a macrolide-resistant isolate in a nursery school in China. Antimicrob Agents Chemother. 2012;56(7):3748-52. https://doi.org/10.1128/AAC.00142-1256.

19. Wang Y, Ye Q, Yang D, Ni Z, Chen Z. Study of two separate types of macrolide-resistant Mycoplasma pneumoniae outbreaks. Antimicrob Agents Chemother. 2016;60(7):4310-4. https://doi.org/10.1128/AAC.00198-16.

20. Li AH, Zhang TG, Shi WX, et al. A comparison of three methods for detecting respiratory viruse. Chin J Microbiol Immunol. 2013;33(7):541-4. https://doi.org/10.3760/cma.j.issn.0254-5101.2013.07.012.

21. Zhao F, Liu L, Tao X, He L, Meng F, Zhang J. Culture-independent detection and genotyping of Mycoplasma pneumoniae in clinical specimens from Beijing, China. PLoS One. 2015;10(10):e0141702. https://doi.org/10.1371/journal.pone.0141702.

22. Matsuoka M, Narita M, Okazaki N, Ohya H, Yamazaki T, Ouchi K, et al. Characterization and molecular analysis of macrolide-resistant Mycoplasma pneumoniae clinical isolates obtained in Japan. Antimicrob Agents Chemother. 2004:48:4624-30. https://doi.org/10.1128/AAC.48.12.4624-4630.

23. Walter ND, Grant GB, Bandy U, Alexander NE, Winchell JM, Jordan HT, Sejvar JJ, et al. Community outbreak of Mycoplasma pneumoniae infection: school-based cluster of neurologic disease associated with household transmission of respiratory illness. J Infect Dis. 2008;198(9):1365-74. https://doi.org/10.1086/592281.

24. Morozumi M, Iwata S, Hasegawa K, Chiba N, Takayanagi R, Matsubara K, et al. Acute Respiratory Diseases Study Group. Increased macrolide resistance of Mycoplasma pneumoniae in pediatric patients with community-acquired pneumonia. Antimicrob Agents Chemother. 2008;52 348-50. https://doi.org/10.1128/AAC.00779-07.

25. Matsubara K, Morozumi M, Okada T, Matsushima T, Komiyama O, Shoji M, et al. A comparative clinical study of macrolide-sensitive and macrolideresistant Mycoplasma pneumoniae infections in pediatric patients. J Infect Chemother. 2009;15(6):380-3.

26. Zhou Y, Zhang Y, Sheng Y, Zhang L, Shen Z, Chen Z. More complications occur in macrolide-resistant than in macrolide-sensitive Mycoplasma pneumoniae pneumonia. Antimicrob Agents Chemother. 2014;58(2):1034-8. https://doi.org/10.1128/AAC.01806-13.

\section{Publisher's Note}

Springer Nature remains neutral with regard to jurisdictional claims in published maps and institutional affiliations.

\section{Ready to submit your research? Choose BMC and benefit from:}

- fast, convenient online submission

- thorough peer review by experienced researchers in your field

- rapid publication on acceptance

- support for research data, including large and complex data types

- gold Open Access which fosters wider collaboration and increased citations

- maximum visibility for your research: over $100 \mathrm{M}$ website views per year

At $\mathrm{BMC}$, research is always in progress.

Learn more biomedcentral.com/submissions 